\title{
Gamification: Classification of the Users Based on Player Types and Motivations
}

\section{Edwin Tunggawan}

Department of Information Technology, Swiss German University, Tangerang 15143, Indonesia

\section{Article Information}

Received: 15 August 2018

Accepted: 20 September 2018

Published: 3 October 2018

DOI: $10.33555 /$ ejaict.v5i2.48

Corresponding Author:

Edwin Tunggawan

Email:

ISSN $\quad 2355-1771$

\section{ABSTRACT}

A comparison between two methods to understand the players' behavior in games. The first one is the player types model by Richard Bartle, and the second is the motivations model by Nick Yee. It's concluded that Yee's model is better when the developers need a more detailed understanding on their users, while Bartle' $s$ model is better to use when the developers need to classify the users in a quicker and simpler way.

Keywords: Gamification, Game 


\section{Introduction}

Gamification is relatively new to the scene of computer software, web, and some other applications. The main idea behind gamification is the use of game mechanics to drive user engagement on the applications and services (Kim A.J.). UX (user experience) used to be a strange phenomenon in HCI (human-computer interaction) scene, shifting the trends of usability and task-oriented approaches to aesthetic and hedonistic approaches (Hassenzahl M, Transticky N, 2006) and the trends of software with beautiful user interface rose.

As gamification's main points lie in game mechanics, it can be assumed that the engagements of the users will have similar motivations with those who play games.

Despite the same basis on game mechanics, gamification in general is different with game design. In gamified applications the fun and functionality must have a balance and the objectives set by the gamification shouldn't harm the functionality (Jones S, 2014). While in real games, even if the objectives of the game is still considered very important, the fun factor makes more than half of the game and the game itself has no other purpose than to be fun and entertaining. A game like Tetris (Bartle R.) could have no other objectives than to keep the player stacking blocks and get more points, as it has no other functionality other than to be played.

Gamification is closely related to games, and some of the theories in gamification is the same with the one used in games. In games, there are theories about the players' actions in a game. Two of the theories are Bartle's and Yee's.

The objective of this paper is to compare the model proposed by Richard Bartle and the one proposed by Nick Yee. This paper will explain how their models could be applicable in an actual gamification project to understand our users' better.

\section{Methodology}

The research consists of literature studies and doing comparisons on the models proposed by Bartle and Yee. Here's a diagram showing how this paper's research was done.

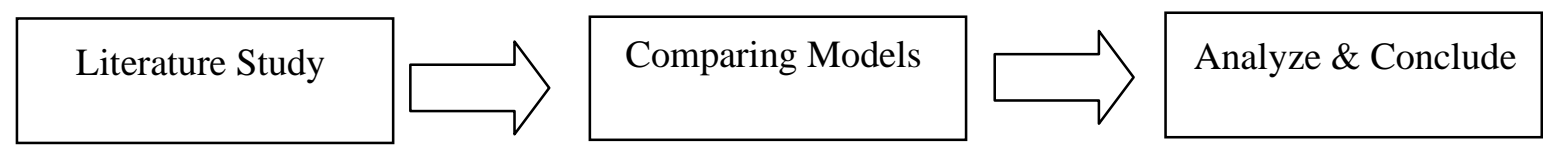

Fig. 1. Research Methodology. 
After doing the literature study needed to gain understanding on both models, the models are compared to each other. Based on the comparison, an analysis is done and the conclusion is made.

The research is purely a conceptual qualitative research, because there's a lack of available data on how the models are applied in real gamification project up to this point.

\section{Richard Bartle's Model}

According to Bartle (Ferro L, Walz S, 2013)., there are four player types in a MUD (MultiUser Dungeon) games. These player types are used as a basis for gamification, for the developers to drive their users to do a particular action on their applications.

Here are the player types as summarized.

- Achievers: doing things to the game world, proud of their status in the game

- Explorers: interacting with the game world, proud of their knowledge

- Socializers: interacting with other players, proud of their friendships and influences

- Killers: doing things to the other players regardless of the other party's consent, proud of their reputation and skills

By looking at the interests of each player types, developers can find a way to drive their users to do a specific action by making use of the users' personality and nature.

Bartle modeled the four player types based on their action when playing the game, while Yee's model focus on their motivation.

Bartle's model is highly tied to the MUD game, but it has been used as a model to define users' type in gamification. Ferro and Walz (Twitter, 2014) mapped Twitter [8] users' position on Bartle's model based on their way of using Twitter.

- Achievers: focusing on status, goals, and completion, raising their status in the community via number of followers, retweets, and so on

- Explorers: focusing on exploring and discovering, don't have much influence in the community, but seek to understand it

- Socializers: focusing on socializing and developing networks, interacting with as many people as possible and driving the flow of information

- Killers: focusing on competition, winning, and rank, pushing out information and attract like-minded users

Bartle's model can be simplified into a 2x2 matrix.

Table 1. Bartle's Model (Ferro L, Walz S, 2013).

\begin{tabular}{lll}
\hline & System & Fellow \\
& & Users \\
\hline Interacting with & Explorers & Socializers \\
Acting on & Achievers & Killers \\
\hline
\end{tabular}

\section{Nick Yee's Model}

There are three main components of a player's motivation in a MMORPG (massively multiplayer online role-playing game) (Yee N) as described by Nick Yee in the Daedalus Project. 
- Achievement: advancement, mechanics, competition

- Social: socializing, relationship, teamwork

- Immersion: discovery, role-play, customization, escapism

According to Yee, these three are the main motivations for players in a game. These are the components forming the player's style of playing. Yet, having one of these three doesn't always make the respective player lose the other two. A very competitive player can be highly driven by achievement, but his competitiveness doesn't make him any less motivated for socializing and interacting with other players. He can be both a competitive player driven by achievement and a socializer wanting to make more friends through the game.

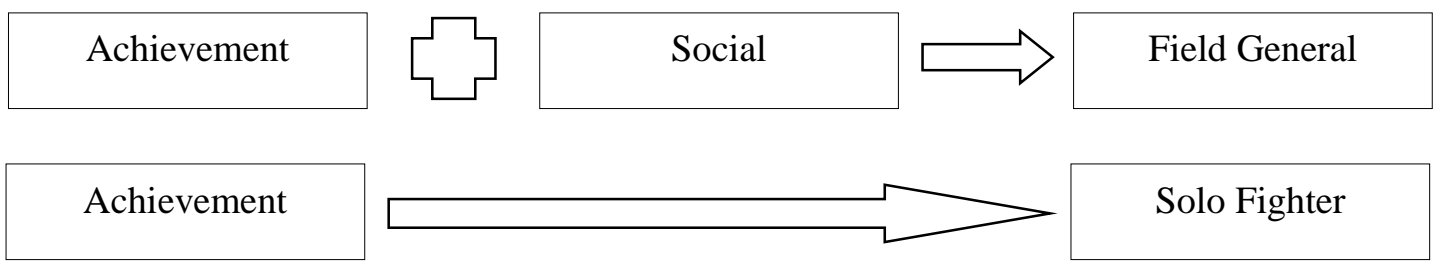

Fig. 2. How the different combinations could drive the user to take a totally different role in the game.

If explained using Twitter reference as Ferro and Walz did for Bartle's model Twitter, (2014), according to Yee it's possible for someone who's pursuing a high social status on Twitter to understand the how the system works by exploring it. It's all a matter of the motivations behind his actions.

\section{Bartle vs Yee}

Bartle's model focused on classifying the players based on their in-game actions, while Yee classifying the players based on their motivation to play the game. These models can be combined to give a more detailed classification of the players.

Despite of Bartle's rough way to classify the player types, Bartle's model can be used to take the most dominant tendency of the players and categorize them into one of the four types to get a rough classification of the users and what they're going to do with the gamification features before starting to gamify. The fact that Bartle's model is still the primary model used as the basis for gamification nowadays is enough to prove that.

Yee's motivational model needs a more detailed data gathering and statistic calculations to get more detailed information on the users during the research. Yee argues that people don't fit in boxes (Yee $\mathrm{N}$ ), and he prefers to use a bi-modal distribution graph to represent the classification of the players based on the survey he did.

Yee's motivational model put the motivations for achievement, social, and immersion as a component that forms a player's playing style and opposed Bartle's theory that the playing style of a player is driven by one primary motivation. Since the motivations are just a component, the overall playing style of a particular player is based on the overall points of each components in his motivation.

Bartle argues that every player can only have one primary motivation that will move him towards either acting or interacting, with either the world or other players as the target. On the other hand, Yee's model on the motivation make it possible to differ the classification for two 
players with a totally different motivation behind their actions, but fall within the same category in Bartle's model (Yee N). In Yee's model, having a high motivation in achievements doesn't necessarily make a player any less in social motivation. But the difference in the components forming the respective player's motivation can greatly affect the way he plays.

The differences can be mapped into the following table.

Table 2. Comparison of Both Models.

\begin{tabular}{lll}
\hline & Bartle & Yee \\
$\begin{array}{l}\text { How the information can be } \\
\text { gathered }\end{array}$ & Observation & Survey \\
$\begin{array}{l}\text { What information is needed } \\
\text { prow the information is }\end{array}$ & $\begin{array}{l}\text { Users' actions } \\
\text { Each user is classified into } \\
\text { one of the four player types }\end{array}$ & $\begin{array}{l}\text { Users' motivations } \\
\text { Statistical distribution graphs } \\
\text { are made for the data gathered } \\
\text { from the users }\end{array}$ \\
$\begin{array}{l}\text { Is it difficult to do } \\
\begin{array}{l}\text { Not very difficult, can be } \\
\text { done by simply observing the } \\
\text { users' actions }\end{array}\end{array}$ & $\begin{array}{l}\text { A bit difficult, since the } \\
\text { survey have to be done } \\
\text { thoroughly and the users are } \\
\text { classified into different } \\
\text { genders and age range }\end{array}$ \\
\hline
\end{tabular}

\section{Conclusions}

Yee's motivation component model explained how the players' playing style is formed. While Yee's model might be more accurate than Bartle's model in explaining the players' style, to understand our users using Yee's model would require us to do a thorough survey.

On the other hand, Bartle's model has some flaws in classifying the players to four categories. Indeed, Yee has proven that the players can't be divided into just four categories. But Bartle's way can be done by simply observing the users and categorizing them into one of the four types, which is a big advantage of Bartle's model compared to Yee's model.

The best model between the two highly depends on the needs of the developers. Yee's model will give a better insight to the developers when they need a more detailed psychological understanding of their users. Yee's model requires the developers to survey the users and analyze the results thoroughly, and then drawing statistical tables and graphs based on the results.

Bartle's model is the ideal method to choose when the developers need to make a quick and simple picture of the kinds of users that will use their system. It can be done by observing the users' interactions with the system and another user, and classifying the actions they do into the four types. 


\section{References}

Bartle R. Hearts. Clubs, Diamonds, Spades: Players Who Suit MUDs. http://mud.co.uk/richard/hcds.htm.

Ferro L, Walz S. (2013). Like this: How game elements in social media and collaboration are changing the flow of the information.

Hassenzahl M, Transticky N. (2006). User experience - a research agenda. In: Behavior \& Information Technology, London: Taylor \& Francis; 91-97.

Jones S. (2014). Gamification vs. Game-Based Learning: Theories, Methods, and Controversies.

Tetris, http://www.tetris.com/

Kim A.J. Putting the Fun in Functional - applying game mechanics to functional software.

Twitter, (2014). http://www.twitter.com/

Yee N. Motivations of Play in MMORPGs. 